\title{
An In Vitro Human Muscle Preparation Suitable for Metabolic Studies Decreased Insulin Stimulation of Glucose Transport in Muscle from Morbidly Obese and Diabetic Subjects
}

\author{
G. Lynis Dohm, Edward B. Tapscott, Walter J. Pories, David J. Dabbs, Edward G. Flickinger, Diane Meelheim, \\ Tohru Fushiki, Samuel M. Atkinson, Charles W. Elton, and Jose F. Caro \\ Departments of Biochemistry, Surgery, Clinical Pathology and Diagnostic Medicine, Obstetrics and Gynecology, and Medicine, \\ School of Medicine, East Carolina University, Greenville, North Carolina 27858
}

\begin{abstract}
We have developed an in vitro muscle preparation suitable for metabolic studies with human muscle tissue and have investigated the effects of obesity and non-insulin-dependent diabetes mellitus (NIDDM) on glucose transport. Transport of 3-Omethylglucose and 2-deoxyglucose was stimulated approximately twofold by insulin in muscle from normal nonobese subjects and stimulation occurred in the normal physiological range of insulin concentrations. In contrast to insulin stimulation of 3-O-methylglucose and 2-deoxyglucose transport in muscle from normal, nonobese subjects, tissue from morbidly obese subjects, with or without NIDDM, were not responsive to insulin. Maximal 3- $O$-methylglucose transport was lower in muscle of obese than nonobese subjects.

Morbidly obese patients, with or without NIDDM, have a severe state of insulin resistance in glucose transport. The novel in vitro human skeletal muscle preparation herein described should be useful in investigating the mechanism of this insulin resistance.
\end{abstract}

\section{Introduction}

The cardinal manifestation of diabetes is hyperglycemia, which in the patient with non-insulin-dependent diabetes mellitus (NIDDM), ${ }^{1}$ is most likely due to tissue resistance to insulin action and relative insulin deficiency. In the postprandial state the hyperglycemia seems to be primarily caused by insulin resistance of glucose transport and utilization in the peripheral tissues, whereas in the fasting condition overproduction of glucose by the liver appears to be the primary cause of hyperglycemia (1-4). Approximately $85 \%$ of a glucose load is taken up by skeletal muscle in a normal individual and in NIDDM insulin resistance in muscle makes a very large contribution to the observed postprandial hyperglycemia (2).

In vivo techniques, such as the euglycemic clamp, have been extremely important in defining the changes that occur in diabetes. However, if the mechanisms underlying insulin resistance are to be understood, one must be able to study the

Address reprint requests to Dr. Dohm, Department of Biochemistry, School of Medicine, East Carolina University, Greenville, NC 27858.

Received for publication 8 September 1986 and in revised form 7 March 1988.

1. Abbreviations used in this paper: NIDDM, non-insulin-dependent diabetes mellitus.

J. Clin. Invest.

(C) The American Society for Clinical Investigation, Inc.

0021-9738/88/08/0486/09 \$2.00

Volume 82, August 1988, 486-494 insulin resistance in in vitro preparations of skeletal muscle. We have developed such a preparation using muscle samples from morbidly obese and nonobese patients undergoing abdominal surgery. Thin muscle strips are mounted in clamps at resting length and incubated in vitro in a manner analogous to the stripped soleus muscle preparations from rats. This human muscle preparation is metabolically viable and structurally intact, and is responsive to insulin. We herein report the procedures for preparation and incubation of this muscle preparation, the data demonstrating its viability, and measurements of 3-O-methylglucose and 2-deoxyglucose transport in muscle of nonobese subjects and morbidly obese subjects with and without NIDDM.

\section{Methods}

Materials. [Methyl- $\left.{ }^{3} \mathrm{H}\right] 3-O-$ methyl-D-glucose $(20-60 \mathrm{Ci} / \mathrm{mmol})$ and [U- ${ }^{14} \mathrm{C}$ ]sorbitol ( $\left.150-250 \mathrm{mCi} / \mathrm{mmol}\right)$ were obtained from ICN Radiochemicals, Irvine, CA. 2-[1,2- $\left.{ }^{3} \mathrm{H}(\mathrm{N})\right]-$ Deoxy-D-glucose $(30.2 \mathrm{Ci} / \mathrm{mmol})$ was obtained from New England Nuclear, Boston, MA. Unless otherwise stated, all other chemicals were obtained from Sigma Chemical Co., St. Louis, MO.

Human subjects. 9 nonobese patients, 11 morbidly obese patients with normal glucose tolerance, and 10 morbidly obese patients with NIDDM served as subjects. One nonobese patient was a kidney donor while the remainder had elective hysterectomies. Two of the morbidly obese patients had hysterectomy surgery while the remainder had gastric bypass surgery for the treatment of their obesity. The physical characteristics of the subject groups are shown in Table I.

None of the subjects had any diseases or had taken any medications known to alter carbohydrate metabolism for at least 3 wk before surgery. The experimental protocol was explained to all subjects and informed consent was obtained. The project was approved by the East Carolina University Policy and Review Committee on Human Research. All subjects had maintained constant body weight during the months preceding admission. Records of food intake of the morbidly obese patients demonstrate that $\sim 15 \%$ of the calories were derived from proteins, $39 \%$ from fat, and $49 \%$ from carbohydrates, which is the typical distribution of calories for this population of patients in North Carolina (5). Because of the effect that the caloric intake and its distribution might have on this study, the morbidly obese subjects were admitted into the hospital $4 \mathrm{~d}$ before surgery. During this period, they remained active at approximately their prehospital exercise level. They received a weight-maintaining diet providing $50 \%$ of the calories as carbohydrates, $30 \%$ as fat (polyunsaturated/saturated fat ratio of 0.4 and cholesterol content of $600 \mathrm{mg}$ ), and $20 \%$ protein. Every morbidly obese patient without known diabetes mellitus had a 75-g oral glucose tolerance test as an outpatient. Their carbohydrate intake was $>150 \mathrm{~g}$ daily for the preceding $3 \mathrm{~d}$ before the test. The criteria of the National Diabetes Data Group (6) were used to classify these patients as nondiabetics. Oral glucose tolerance tests were not performed in the morbidly obese patients who had previously been diagnosed as having diabetes.

The subjects underwent surgery after an overnight fast. General anesthesia was induced with a short-acting barbituate, and maintained by phentanyl and nitrous oxide-oxygen mixture. Only saline was given 
Table I. Clinical and Biochemical Data of Nonobese, Obese-Nondiabetic, and Obese-NIDDM Subjects

\begin{tabular}{lccccc}
\hline & Age & Body weight & Body mass index & Fasting glucose & Fasting insulin \\
\hline & $y r$ & $k g$ & $k g / m^{2}$ & $m g / d l$ & $\mu U / m l$ \\
Nonobese (8 females) & $37 \pm 2$ & $60 \pm 3$ & $22 \pm 1$ & $95 \pm 5$ & Not determined \\
Obese-nondiabetic (11 females) & $35 \pm 2$ & $127 \pm 9^{*}$ & $47 \pm 3^{*}$ & $102 \pm 4$ & $42 \pm 8$ \\
Obese-NIDDM (7 females) & $36 \pm 3$ & $119 \pm 4^{*}$ & $46 \pm 2^{*}$ & $135 \pm 9^{* \delta}$ & $46 \pm 5$ \\
Obese-NIDDM (3 males) & $27 \pm 5$ & $182 \pm 29^{* \pm}$ & $55 \pm 9^{*}$ & $204 \pm 27^{* \neq}$ & $75 \pm 2$ \\
& & & & & \\
\hline
\end{tabular}

Values are mean \pm SEM. * Significantly different $(P<0.05)$ than the nonobese group. ${ }^{\ddagger}$ Significant difference $(P<0.05)$ between obeseNIDDM (female) and obese-NIDDM (male) groups. ${ }^{\S}$ Significant difference $(P<0.05)$ between obese-nondiabetic and obese-NIDDM.

intravenously before the biopsy. After opening the abdomen, a biopsy $3 \times 2 \times 2 \mathrm{~cm}$ from the rectus abdominus muscle was excised from the incision area.

Human muscle strip preparation. A human muscle preparation was modelled after the stripped rat soleus muscle preparations in rats (7). To mount muscle at in vivo length, we constructed two sets of clamps: one was $3 \mathrm{~cm}$ wide (constructed from two pairs of hemostats) and the second was $1.5 \mathrm{~cm}$ wide (constructed from two pieces of plexiglass with a fulcrum). The surgeon places a $3-\mathrm{cm}$ clamp on the muscle before it is excised. After excision the muscle sample and the 3-cm clamp are placed in oxygenated Krebs-Henseleit buffer for rapid transport back to the laboratory ( $\sim 5 \mathrm{~min}$ ). In the laboratory, muscle fiber strips weighing 50-80 mg are "teased" from the mounted muscle sample and a smaller clamp is placed on the muscle strip before it is cut free. The muscle fiber strips are $12-14 \mathrm{~mm}$ long, 3-5 mm wide, and 0.5-1.0 $\mathrm{mm}$ thick. From a muscle sample that is $3 \times 2 \times 2 \mathrm{~cm}$ we can prepare 8-12 muscle strips in 10-15 min. Pictures of a muscle sample in the $3-\mathrm{cm}$ clamp and a muscle strip in the $1.5-\mathrm{cm}$ clamp are shown in Fig. 1 .

After preparation, the muscle strip and clamp are placed in a specially constructed chamber containing $3.0 \mathrm{ml}$ of Krebs-Henseleit buffer with $1 \%$ bovine serum albumin (fatty acid poor, dialyzed against Krebs-Henseleit buffer), and either $5 \mathrm{mM}$ glucose or $1 \mathrm{mM}$ pyruvate. The chamber was constructed of plexiglass to consist of 12 chambers (each $3 \mathrm{~cm}$ long, $1.5 \mathrm{~cm}$ wide, and $3 \mathrm{~cm}$ deep) with a lid fitted with tubing so that each chamber could be gassed with $\mathrm{O}_{2} / \mathrm{CO}_{2}$ (95\%:5\%). The chamber was fitted in a shaking water bath at $37^{\circ} \mathrm{C}$.

Ultrastructural analysis. Tissue for electron microscopy was fixed in one-half strength Karnovsky's fixative, postfixed in osmium tetroxide, sectioned at $60-90 \mathrm{~nm}$, and stained with uranyl acetate and lead citrate. Ultrathin sections were examined on a Zeiss EM 109 (Carl Zeiss, Inc., Thornwood, NY).

Metabolite analysis. To demonstrate the metabolic viability of this muscle preparation, muscle strips were prepared and incubated for $\mathbf{4 0}$ min with $1 \mathrm{mM}$ pyruvate as substrate as described above and then the muscle strips were frozen in liquid nitrogen. For comparison a small portion of the muscle sample was also quickly frozen between aluminum clamps cooled in liquid nitrogen immediately after it was removed (sample designated fresh). The frozen muscle samples were weighed and homogenized for $10 \mathrm{~s}$ in a Polytron homogenizer in $9 \mathrm{vol}$ of ice-cold $7 \%$ perchloric acid. The homogenates were centrifuged and the supernates were neutralized with $2 \mathrm{~N} \mathrm{~K}_{2} \mathrm{CO}_{3}$ containing $100 \mathrm{mM}$ triethanolamine. The precipitated $\mathrm{KClO}_{4}$ was separated by centrifugation and the supernate solutions were assayed for ATP, ADP, and AMP and creatine phosphate by fluorimetric enzymatic assays (8).

3-O-Methylglucose and 2-deoxyglucose transport. The procedure for 3-O-methylglucose uptake in muscle fiber strips was an adaptation of the method described by Wallberg-Henriksson and Holloszy (9) for rat muscle incubations. The human muscle fiber strips, mounted in $1.5-\mathrm{cm}$ clamps, were incubated in $3.0 \mathrm{ml}$ of medium consisting of Krebs-Henseleit buffer, $1 \%$ bovine serum albumin, $1.0 \mathrm{mM}$ pyruvate, and porcine insulin $\left(0-10^{-7} \mathrm{M}\right)$. The mixture was gassed with $\mathrm{O}_{2} / \mathrm{CO}_{2}$ (95\%:5\%) and the muscles were allowed to preincubate for $30 \mathrm{~min}$.
After the preincubation $30 \mu \mathrm{l}$ of the following solution was added: 2.0 $\mathrm{M}$ sorbitol, $0.5 \mathrm{M} \mathrm{3-O-methylglucose}$ containing $10 \mu \mathrm{Ci} / \mathrm{ml}\left[{ }^{14} \mathrm{C}\right]-$ sorbitol and $20 \mu \mathrm{Ci} / \mathrm{ml}\left[{ }^{3} \mathrm{H}\right] 3-O$-methylglucose. Final concentrations were $5.0 \mathrm{mM} \mathrm{3-O-methylglucose}$ and $20 \mathrm{mM}$ sorbitol. The mixture was then gassed again and incubated for precisely $10 \mathrm{~min}$. The muscles were quickly removed from the medium onto a blotter, rinsed in a stream of Krebs-Henseleit buffer, and again blotted to remove excess moisture. The muscle strips were weighed within $5 \mathrm{~min}$ and oxidized in a Packard 306 sample oxidizer (Packard Instrument Co., Inc., Downers Grove, IL) to determine ${ }^{14} \mathrm{C}$ and ${ }^{3} \mathrm{H}$ radioactivity. Accumulation of $\left[{ }^{3} \mathrm{H}\right] 3-O$-methylglucose was corrected for the $\left[{ }^{14} \mathrm{C}\right]$ sorbitol space.

2-Deoxyglucose uptake was assayed as described for 3-O-methylglucose except that $\left[{ }^{3} \mathrm{H}\right] 2$-deoxyglucose $(0.04 \mu \mathrm{Ci} / \mu \mathrm{mol})$ replaced 3-Omethylglucose and the reaction was extended to $60 \mathrm{~min}$. After the incubation period, the muscle fiber strips and clamps were blotted lightly and transferred to a chamber containing $4.0 \mathrm{ml}$ of ice-cold Krebs-Henseleit buffer. After a 5-min postincubation the buffer was changed and the muscle fiber strips were again postincubated for $5 \mathrm{~min}$ to remove extracellular $\left[{ }^{3} \mathrm{H}\right] 2$-deoxyglucose. The muscle was then removed, blotted, trimmed from the clip, weighed, lyophilized, weighed again, solubilized, and counted by liquid scintillation for ${ }^{3} \mathrm{H}$ and ${ }^{14} \mathrm{C}$ radioactivity. The small amount of extracellular 2-deoxyglucose remaining was corrected from the sorbitol remaining in the sample.

\section{Results}

To establish that our muscle preparation was appropriate for the metabolic studies that we planned to conduct, it was necessary to demonstrate that the in vitro incubated muscle fiber strips were viable. To show that the muscle preparation was structurally intact and had normal membrane structure, we performed electron-microscopic examination of fresh and incubated muscle. The most sensitive indicators of metabolic viability are the energy charge of the muscle and the ability to respond to hormones. Therefore we measured the concentrations of the energy-linked metabolites in fresh and incubated muscle and determined the degree of insulin stimulation of glucose transport in incubated muscle fiber strips.

Ultrastructure of incubated muscle fiber strips. To establish that in vitro incubation of the muscle fiber strips does not alter the structure of the muscle, electron-microscopic examination of fresh and incubated muscles from obese and nonobese subjects was performed. There was little difference between fresh and incubated muscle ultrastructure. The cells were intact, nuclei showed normal chromatin patterns, the sarcomeres were intact, and there was no appreciable mitochondrial swelling. In Fig. 2 the intact cell membrane of an incubated muscle fiber strip is evident as is the normal architecture of the 


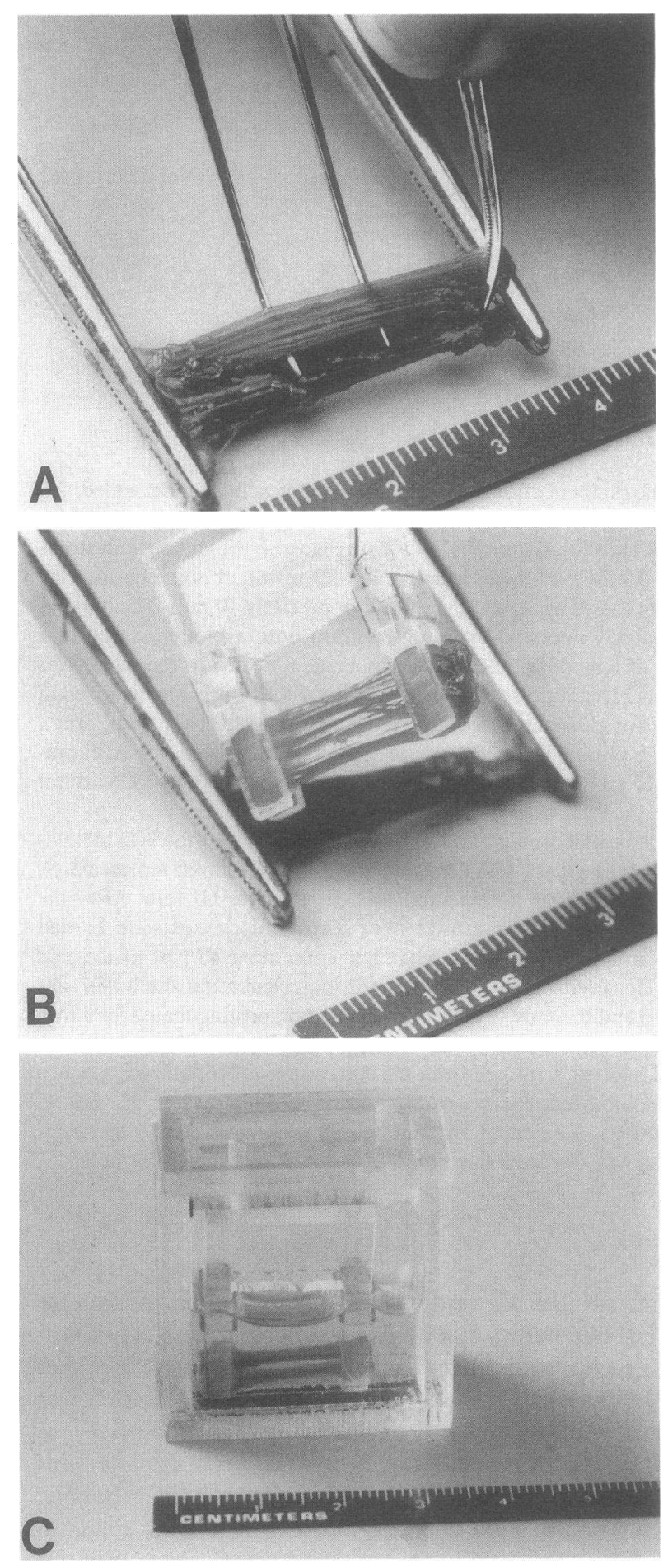

Figure 1. Preparation and incubation of muscle fiber strips. $(A)$ The surgeon places a 3-cm clamp on the muscle before it is excised and then muscle strips weighing 50-100 mg are "teased" loose from the rest of the muscle sample. (B) A $1.5-\mathrm{cm}$ clamp is placed on the muscle fiber strip before it is cut free. $(C)$ The clamp and muscle fiber strip are incubated in $3.0 \mathrm{ml}$ of medium.

muscle. The z-lines are in register and the thick and thin filaments can be seen. The nuclei are well preserved and the mitochondria are intact with distinct cristae.

One of the initial concerns about the muscle fiber strip preparation was whether the sarcolemmal membranes would be sufficiently intact so that transport studies could be performed. To test whether the muscle fiber strips were "leaky," we measured the sorbitol space after various lengths of incubation. The sorbitol space after $20 \mathrm{~min}$ of incubation (Fig. 3) was very similar to that measured at $10 \mathrm{~min}$ in another set of incubations (see Fig. 5) and it did not significantly change after $60 \mathrm{~min}$ of incubation. We take this as evidence for the intactness of the muscle fibers and for the fact that the cut fiber ends are effectively sealed by the clamp. If there had been significant nonspecific diffusion of material into the muscle fiber strip we would have observed a continual increase in the sorbitol space.

Metabolite concentrations in fresh and incubated muscle. The concentrations of ATP, ADP, AMP, and creatine phosphate in fresh (frozen immediately after excision) and incubated muscle fiber strips are shown in Fig. 4. The concentration of ATP was significantly reduced in incubated muscle fiber strips compared to fresh muscle. However, this change is most likely due to a decrease in the total adenine nucleotide pool (10) since the concentrations of creatine phosphate and AMP were not changed and the ATP:(ADP + AMP) ratio was not different in fresh and incubated muscle. In one set of incubated muscle fiber strips we measured the glycogen content before and after incubation. The data (Fig. 4) suggest that there is little net glycogenolysis during the incubation.

3-O-Methylglucose and 2-deoxyglucose transport in incubated muscle fiber strips. Basal 3-O-methylglucose uptake (in the absence of insulin) was $\sim 8 \mathrm{nmol} / \mathrm{min} \cdot \mathrm{g}$ for four of the five nonobese subjects studied (Fig. 5). The fifth subject, however, had a basal uptake rate of $\sim 35 \mathrm{nmol} / \mathrm{min} \cdot \mathrm{g}$ and we designated this subject a "hyperresponder" because of the obvious difference from the other subjects. We examined several clinical parameters of this hyperresponder but found no unusual information that would explain the difference. All five nonobese subjects demonstrated an increase in 3-O-methylglucose transport in response to $10^{-7} \mathrm{M}$ insulin. The average fold stimulation was 2.5 with a range of 1.8-3.0.

One of the difficulties with studying glucose transport with 3-O-methylglucose was that the extracellular 3-O-methylglucose was a high proportion of the total tissue ${ }^{3} \mathrm{H}$ radioactivity (intracellular ${ }^{3} \mathrm{H}$ was $10.1 \pm 1.4 \%$ of the total tissue ${ }^{3} \mathrm{H}$ radioactivity in the basal incubations). This presented a large "blank" value that had to be corrected by the sorbitol space. To lower the extracellular background we decided to use 2-deoxyglucose as a glucose analogue and then rinse out the extracellular 2-deoxyglucose in a postincubation at ice-cold temperatures. This is possible because 2-deoxyglucose is phosphorylated intracellularly by hexokinase and the phosphorylated derivative cannot exit the cell. The cold temperature postincubation was used so that extracellular 2-deoxyglucose could diffuse out but carrier mediated uptake would be very low. Using this method the intracellular $\left[{ }^{3} \mathrm{H}\right.$ ]deoxyglucose was $33 \pm 4 \%$ of the total ${ }^{3} \mathrm{H}$ radioactivity in the tissue incubated in the absence of insulin.

There are two requirements for the use of 2-deoxyglucose for transport studies. First, it must be shown that the rate of transport is linear over the incubation period so that ATP is not being depleted as phosphate is incorporated irreversibly into 2-deoxyglucose. Secondly, it must be demonstrated that phosphorylation of 2-deoxyglucose is not limiting the rate of uptake. We have measured 2-deoxyglucose uptake into muscle fiber strips at $50 \mathrm{mM}$ 2-deoxyglucose in the presence of $10^{-7} \mathrm{M}$ insulin. These conditions were chosen because this should produce the highest transport rate, and thus be the most strin- 


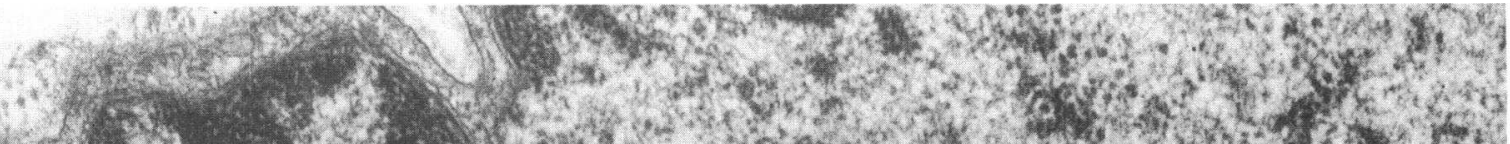

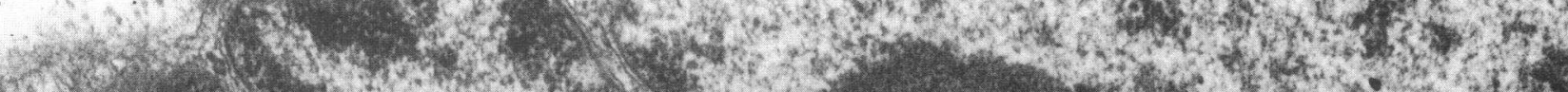

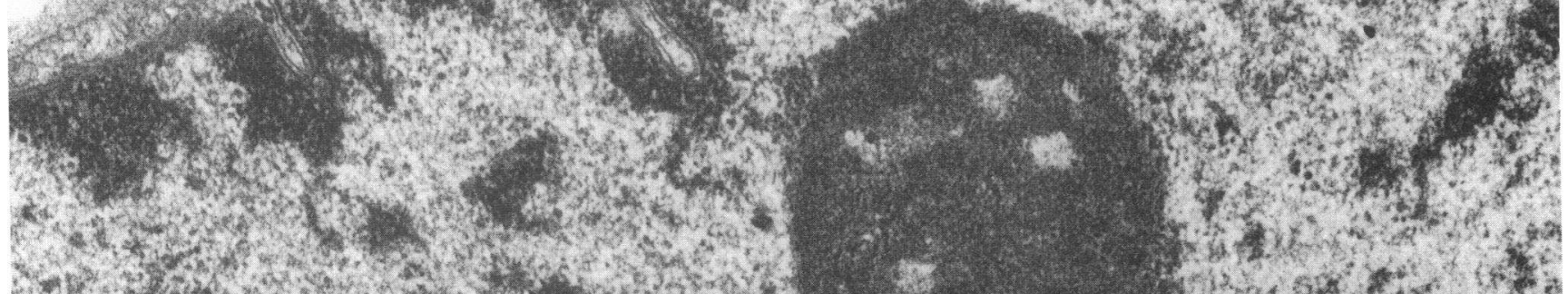

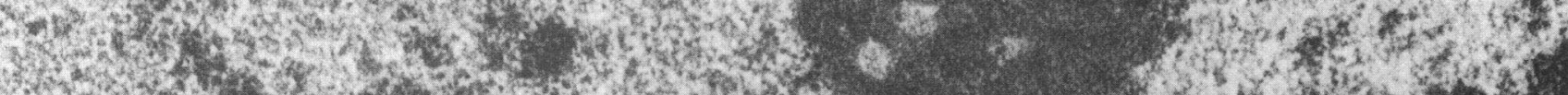

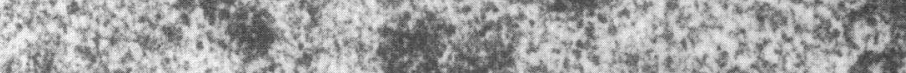

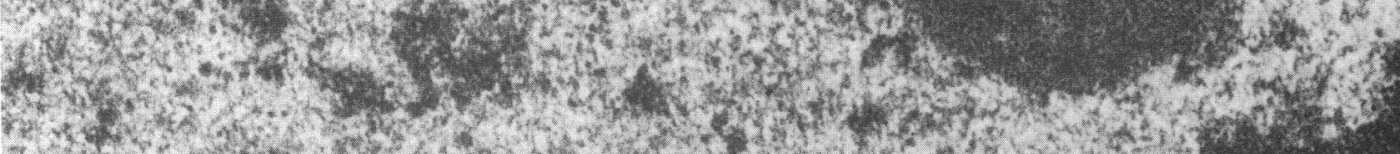

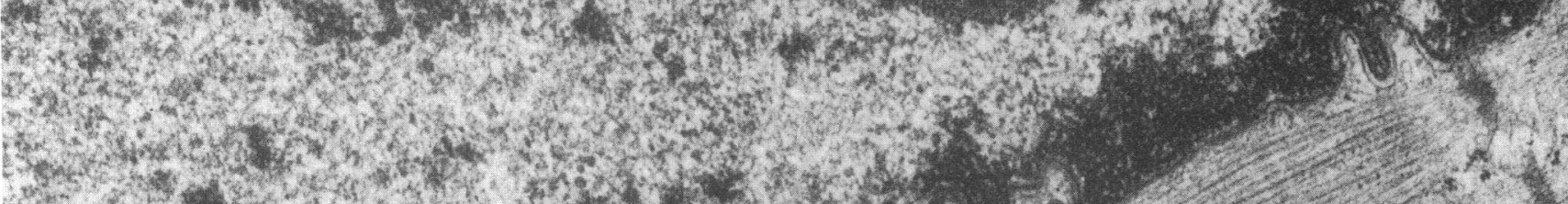

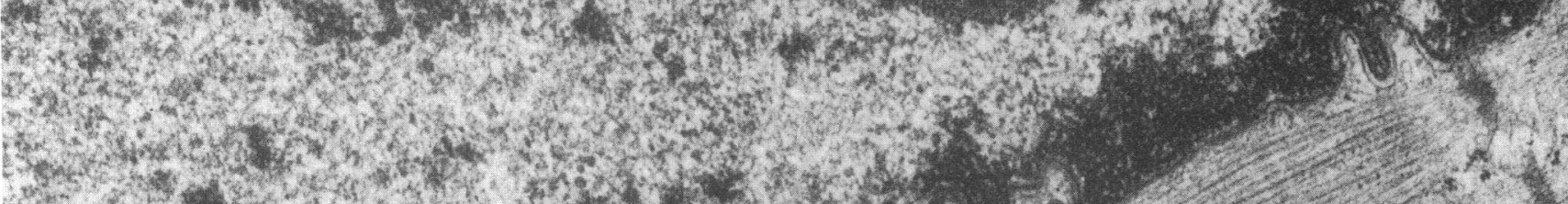

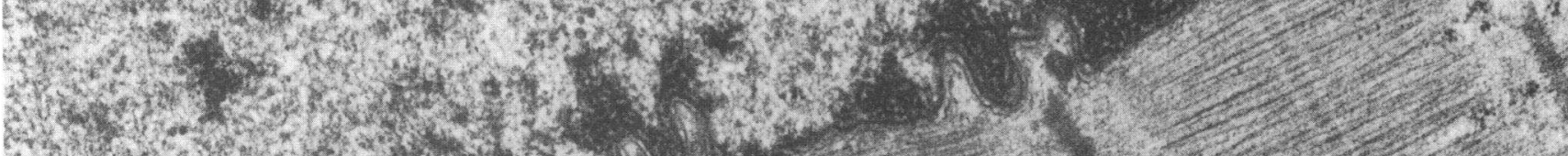

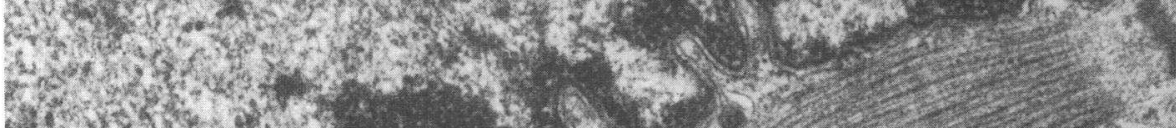
W.

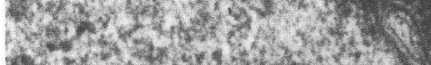

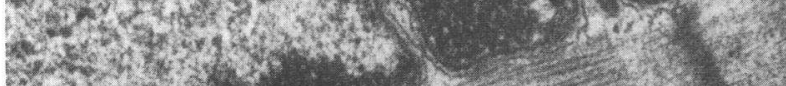

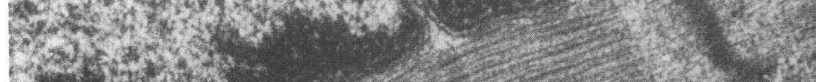
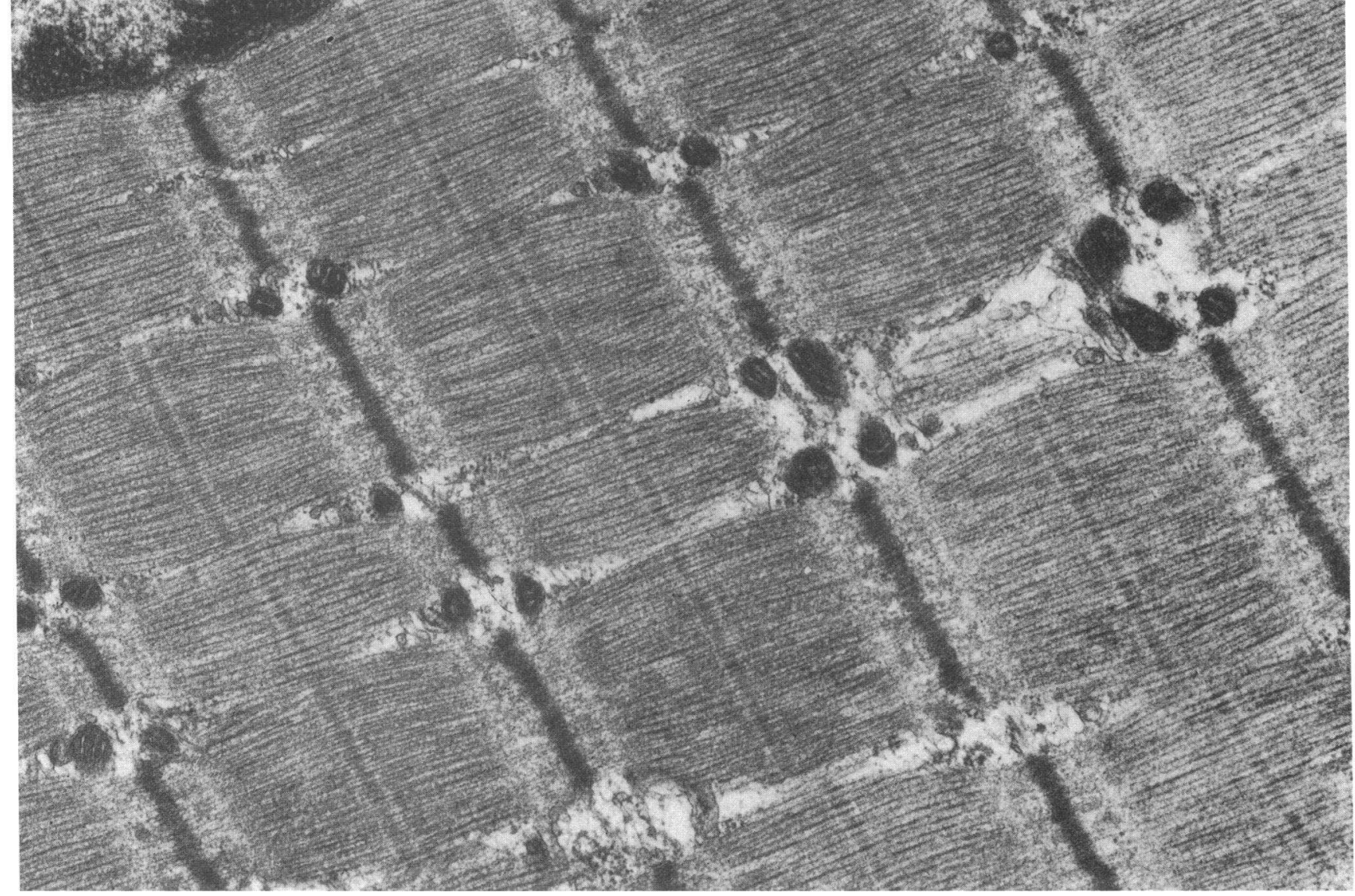

Figure 2. Electron micrograph of an incubated muscle fiber strip. 


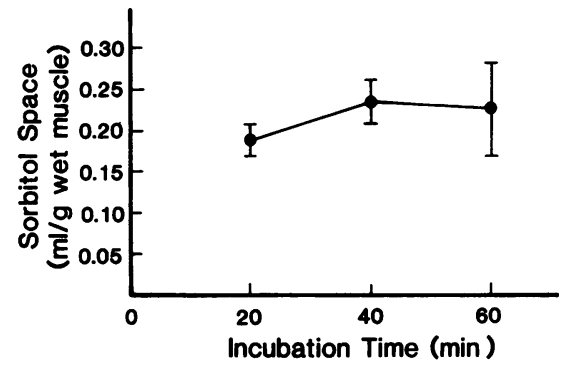

Figure 3. Sorbitol space in muscle fiber strips after varying lengths of incubation. Values are mean \pm SEM for six observations (four nonobese and two obese subjects).

gent test for the requirements of the system. The rate of 2-deoxyglucose uptake was linear for at least $60 \mathrm{~min}$ (Fig. 6) and most of the intracellular 2-deoxyglucose was phosphorylated (84.7 $\pm 0.3 \%$ phosphorylated in the presence of $10^{-7} \mathrm{M}$ insulin and $89.5 \pm 4.1 \%$ phosphorylated without insulin; $n=3$ ). The intracellular concentration of nonphosphorylated 2-deoxyglucose in these incubations was $\sim 1.6 \mathrm{mM}$. These data demonstrate that our assay of 2-deoxyglucose uptake is appropriate to study glucose transport.

2-Deoxyglucose transport into muscle fiber strips was measured in the absence of insulin and at three insulin concentrations to establish an insulin dose-response curve (Fig. 7). Consistent with the 3-O-methylglucose transport data, insulin stimulated 2-deoxyglucose transport approximately twofold and stimulation was in the physiological range of plasma insulin concentrations.

\section{$C=$ Control (quickly frozen) \\ I = Incubated}
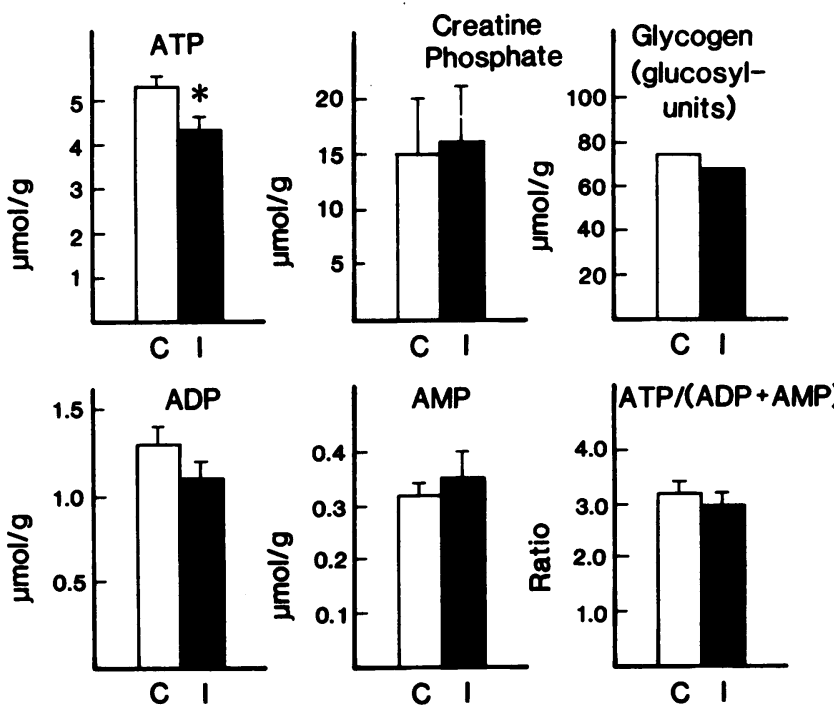

Figure 4. Metabolite levels in control (quickly frozen) and incubated (40 min) muscle samples. Adenine nucleotides were assayed in seven subjects (three obese and four nonobese) while creatine phosphate was assayed in five samples (three obese and two nonobese). The glycogen concentration was determined in one obese subject. *Significant difference $(P<0.05)$ between control and incubated.

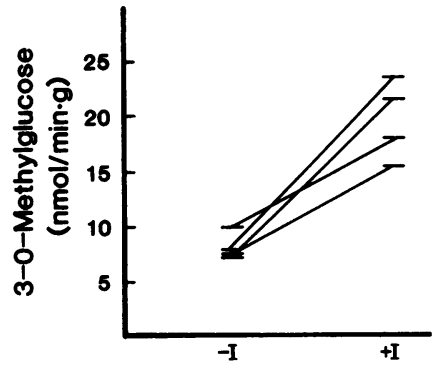

Figure 5. 3-O-Methylglucose transport in muscle fiber strips of nonobese subjects in the absence $(-I)$ or presence $(+I)$ of $10^{-7} \mathrm{M}$ insulin. There was one nonobese sample that had very high 3-O-methylglucose uptake compared to the others and was thus not included in the data shown above. The values for this hyperresponder in the absence and presence of $10^{-7}$ $\mathrm{M}$ insulin were 35.2 and 86.4 $\mathrm{nmol} / \mathrm{min} \cdot \mathrm{g}$.

Glucose transport in muscle fiber strips from obese subjects with and without NIDDM. We developed the muscle fiber strip preparation to investigate insulin action in muscle from human subjects with insulin resistance. Obesity and NIDDM are conditions that lead to insulin resistance (11-14) and therefore we have investigated insulin stimulation of glucose transport in muscle fiber strips from morbidly obese subjects with and without NIDDM.

Representative glucose tolerance curves for the female subjects in the three groups are shown in Fig. 8. The obese subjects with normal glucose tolerance demonstrate insulin resistance because the glucose is held in the normal range by elevated insulin levels. The diabetic subjects have a higher degree of resistance to insulin because glucose levels are elevated above normal in the face of even higher insulin levels. It should be pointed out that the data shown in Fig. 8 for diabetic patients do not include those patients who had been previously diagnosed with diabetes because those patients were not given a glucose tolerance test. The degree of severity of diabetes, therefore, may be greater in the entire diabetic group than that represented by the patients shown in Fig. 8.

Since the composition of muscle could be altered by obesity we investigated the protein, lipid, and water content of muscle samples for our nonobese and obese subjects (Fig. 9). There was a significantly lower sorbitol space in obese muscle but there were no differences in protein, lipid, or total tissue water in incubated muscle fiber strips. We were somewhat surprised that lipid content was not altered in obese samples but our measurement of lipid is consistent with the electronmicroscopic examination because there were no discernable lipid droplets. Apparently the lipid is stored primarily in adipose tissue rather than being infiltrated into other tissues.

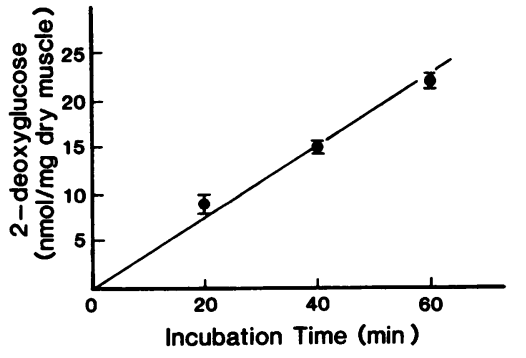

Figure 6. Time course for 2-deoxyglucose uptake into incubated muscle fiber strips. Values are mean \pm SEM for seven observations (four nonobese and three obese subjects). Uptake was measured at $50 \mathrm{mM}$ 2-deoxyglucose in the presence of $10^{-7}$ insulin. 


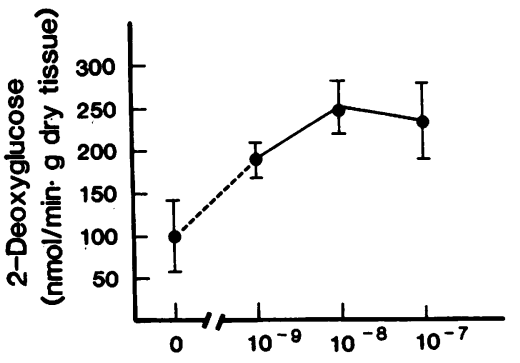

Insulin Concentration (M)
Figure 7. Insulin stimulation of 2-deoxyglucose transport into incubated muscle fiber strips. 2Deoxyglucose uptake was measured in muscle from four nonobese subjects. Three samples demonstrated insulin stimulation and the data is shown in the figure. The values for the samples that did not stimulate were as follows: $97,117,96$, and $93 \mathrm{nmol} / \mathrm{min} \cdot \mathrm{g}$ for 0 , $10^{-10}, 10^{-9}$, and $10^{-7} \mathrm{M}$ insulin, respectively. One of the muscle samples that did show insulin stimulation was taken from the lumbar region of the back in a kidney donation surgery. Since this is a different muscle than the others reported, the individual values are given: $82,163,260$, and $195 \mathrm{nmol} / \mathrm{min} \cdot \mathrm{g}$ for $0,10^{-9}, 10^{-8}$, and $10^{-7} \mathrm{M}$ insulin, respectively.

The ability of incubated muscle fiber strips to maintain energy linked metabolite levels was investigated in samples from obese and nonobese subjects to ascertain that both would remain metabolically viable (Table II). There were no significant differences in the concentrations of ATP, ADP, or AMP between obese and nonobese in the control (quickly frozen) muscle samples, and both groups maintained metabolic energy levels during the incubations.
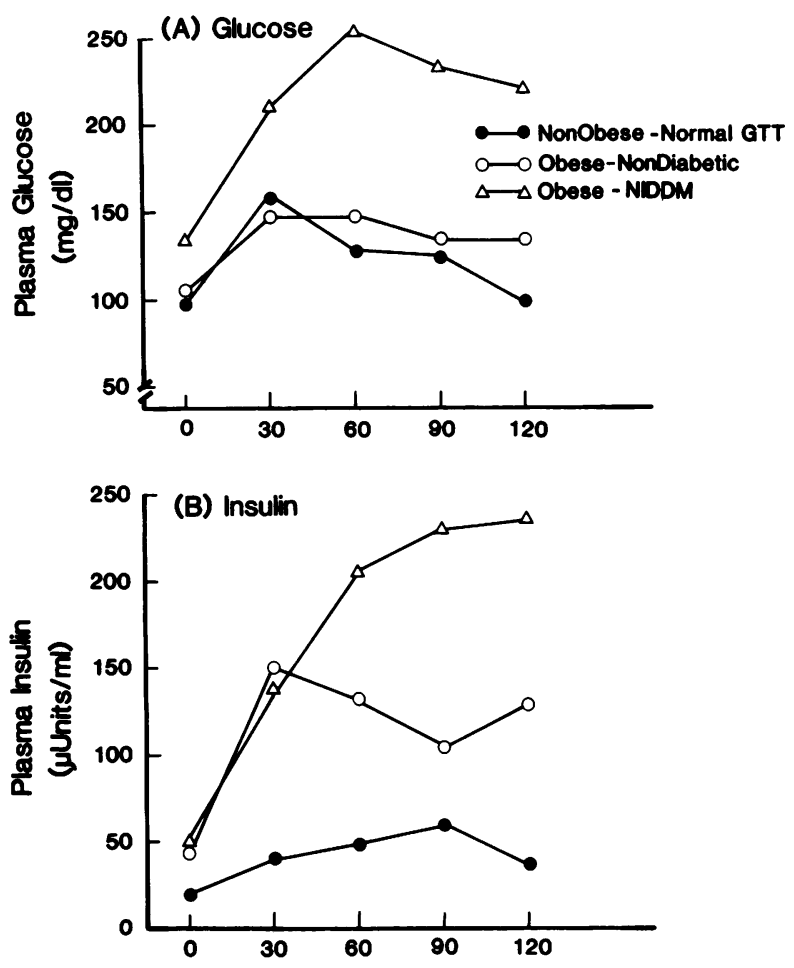

Time After Gucose Load ( $\mathrm{min})$

Figure 8. Plasma glucose and insulin concentrations during an oral glucose tolerance test (GTT). (•) Samples were taken from four nonobese female subjects who did not have surgery. (o) Values from six female morbidly obese patients who subsequently underwent gastric bypass surgery. $(\Delta)$ The obese NIDDM subjects (five females) were unaware of their diabetic condition when they were examined for gastric bypass surgery.
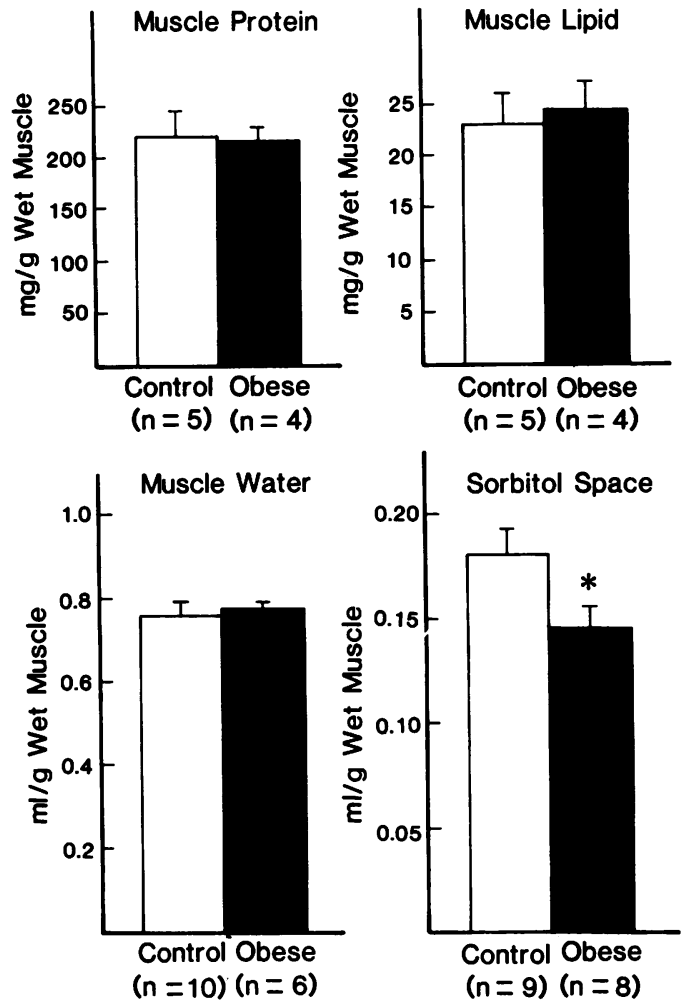

Figure 9. Content of protein, lipid, total tissue water, and extracellular water (sorbitol space) in incubated muscle fiber strips from obese and nonobese subjects. Total tissue water was assayed gravimetrically by difference in weight before and after lyophilization. Sorbitol space was determined from the $\left[{ }^{14} \mathrm{C}\right]$ sorbitol in the incubated tissue as described in Methods. Protein was measured on a tissue homogenate by the Lowry procedure (27). Lipid content was assayed colorimetrically after extraction by a modified Folch procedure (28).

Uptake of 3-O-methylglucose by muscle strips of nondiabetic-obese subjects demonstrated a much greater heterogeneity in both the basal and insulin-stimulated rates (Fig. 10) as well as in the degree of stimulation. As in the nonobese group, there was one muscle sample that had inordinately high rates of 3-O-methylglucose transport (hyperresponder) and the data of that subject is shown in the legend to Fig. 10 but was not included with that of the other six subjects. Muscle strips from four of the seven obese subjects with normal glucose tolerance showed stimulation of 3-O-methylglucose transport in the presence of $10^{-7} \mathrm{M}$ insulin while the other three were unresponsive. This heterogeneity of insulin responsiveness may be

Table II. Adenine Nucleotide Levels in Control (Quickly Frozen) and Incubated Muscle Strips from Nonobese and Obese Subjects

\begin{tabular}{lcccc}
\hline & ATP & ADP & AMP & ATP/(ADP + AMP) \\
\hline Nonobese $(n=4)$ & & & & \\
$\quad$ Control & $5.2 \pm 0.3$ & $1.4 \pm 0.2$ & $0.35 \pm 0.02$ & $3.0 \pm 0.2$ \\
Incubated & $4.1 \pm 0.3$ & $1.1 \pm 0.1$ & $0.35 \pm 0.05$ & $2.9 \pm 0.2$ \\
Obese $(n=3)$ & & & & \\
$\quad$ Control & $6.2 \pm 0.6$ & $1.6 \pm 0.4$ & $0.27 \pm 0.02$ & $3.4 \pm 0.3$ \\
$\quad$ Incubated & $5.0 \pm 0.4$ & $1.1 \pm 0.1$ & $0.33 \pm 0.09$ & $3.6 \pm 0.6$ \\
\hline
\end{tabular}

Values are mean \pm SEM. 


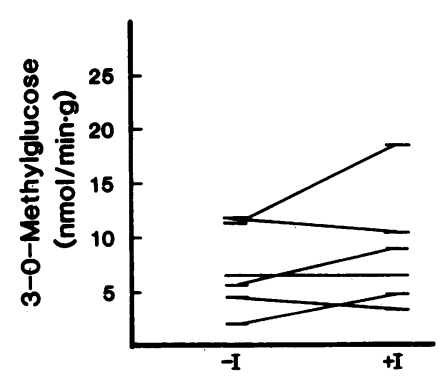

related to the heterogeneous responses that Olefsky et al. (1) and Kolterman et al. (11) observed in in vivo insulin action and glucose transport into adipocytes of obese subjects.

The data for 3-O-methylglucose and 2-deoxyglucose transport are summarized in Fig. 11 and Table III. In muscle from nonobese subjects transport of both glucose analogues was stimulated approximately twofold by insulin. The rates of transport of 3-O-methylglucose and 2-deoxyglucose appear to be dramatically different in Fig. 11 and Table III. The reason for this difference is that uptake of 3-O-methylglucose was expressed per gram of wet tissue and 2-deoxyglucose was expressed on a dry tissue weight basis. Since there was no difference in tissue water between obese and nonobese muscle, either basis of expression should provide a valid comparison. We measured 2-deoxyglucose uptake in muscle strips from nonobese subjects at $5 \mathrm{mM}$ concentration so that a comparison with the rate of 3-O-methylglucose transport could be made. The rates in the absence and presence of $10^{-7} \mathrm{M}$ insulin were 26 and $58 \mathrm{nmol} / \mathrm{min} \cdot \mathrm{g}$ dry tissue (Table III). Since muscle contains $\sim 75 \%$ water this would be $\sim 6.5$ and $14.5 \mathrm{nmol} /$ $\mathrm{min} \cdot \mathrm{g}$ wet tissue, which would compare well with the values of $8 \pm 1$, and $20 \pm 2 \mathrm{nmol} / \mathrm{min} \cdot \mathrm{g}$ wet tissue for 3-O-methylglucose transport in the absence and presence of $10^{-7} \mathrm{M}$ insulin.

By contrast with muscle samples from the nonobese group, there was no statistically significant stimulation of glucose

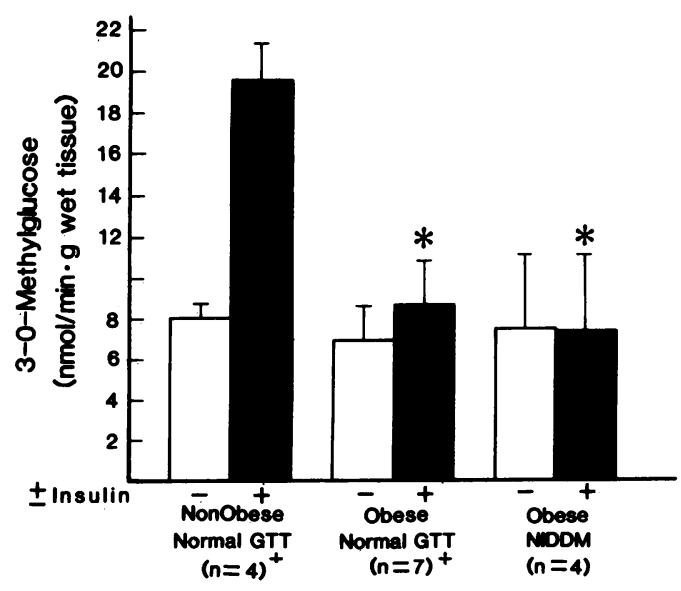

Figure 11. 3-O-Methylglucose transport in muscle fiber strips from nonobese subjects, morbidly obese subjects with normal glucose tolerance, and morbidly obese subjects with NIDDM. *Significantly different $(P<0.05)$ from nonobese group $\left(+\right.$ insulin). ${ }^{+}$Values were taken from Figs. 5 and 10.
Table III. Insulin Stimulation of 2-Deoxyglucose Transport into Muscle Fiber Strips from Nonobese Subjects,

Nondiabetic Morbidly Obese Subjects, and Morbidly Obese Subjects with NIDDM

\begin{tabular}{|c|c|c|c|}
\hline \multirow[b]{2}{*}{ Insulin concentration } & \multicolumn{3}{|c|}{ 2-Deoxyglucose transport } \\
\hline & 0 & $1 \times 10^{-9}$ & Maximal* \\
\hline & \multicolumn{3}{|c|}{$\mathrm{nmol} / \mathrm{min} \cdot \mathrm{g}$ dry muscle } \\
\hline \multicolumn{4}{|l|}{$50 \mathrm{mM}$ 2-deoxyglucose } \\
\hline Nonobese (4) & $100 \pm 25$ & $167 \pm 24$ & $199 \pm 41$ \\
\hline Obese-nondiabetic (4) & $158 \pm 40$ & $171 \pm 33$ & $158 \pm 44$ \\
\hline Obese-NIDDM (6) & $133 \pm 30$ & $152 \pm 35$ & $132 \pm 31$ \\
\hline \multicolumn{4}{|l|}{5 mM 2-deoxyglucose } \\
\hline Nonobese (4) & $26 \pm 3$ & - & $58 \pm 10$ \\
\hline Obese-nondiabetic (2) & $15(12,18)$ & - & $20(18,23)$ \\
\hline Obese-NIDDM (2) & $24(27,22)$ & - & $21(19,24)$ \\
\hline
\end{tabular}

Values are mean \pm SEM. The number of observations is shown in parentheses adjacent to the group. In those instances where there were only two subjects, individual values are given in parentheses following the mean.

* Insulin concentration for experiments with $50 \mathrm{mM}$ 2-deoxyglucose was $1 \times 10^{-7} \mathrm{M}$ while for $5 \mathrm{mM}$ 2-deoxyglucose it was $1 \times 10^{-6} \mathrm{M}$.

transport by insulin in either the obese subjects with normal glucose tolerance or in the patients with NIDDM. In addition, the maximally stimulated rate of 3-O-methylglucose transport was significantly less in the obese-nondiabetic, and the NIDDM groups than in the muscle from nonobese subjects, but there was no difference in transport rates between the obese-nondiabetic and the obese-NIDDM (Fig. 11). These same trends were evident for 2-deoxyglucose transport (Table III).

\section{Discussion}

The many published studies that have utilized isolated hepatocytes and adipocytes demonstrate the importance of in vitro studies in metabolic research. Since muscle is an important target of insulin action, we felt that it was important that an in vitro muscle preparation be developed that could be used on human tissue. The rat muscle preparation that seemed to hold the most promise for adaptation to human tissue was the stripped soleus muscle preparation (7). For this preparation muscle fiber bundles that run the whole length of the muscle are separated and then the tendons are attached to a clip to hold the muscle strip at resting length. By this procedure a muscle that is too large to be incubated intact is reduced to a size that allows free diffusion. In addition, attaching the muscle strip to a clip has the advantage of preventing the usual contraction of the muscle in the incubation medium which further makes diffusion into the interior of the muscle more difficult.

In deciding which muscle to use for a human muscle fiber strip preparation, the rectus abdominus muscle seemed to be a good choice because it was accessible from the incision of most abdominal surgery procedures and longitudinal sections of muscle fibers could be found along a midline incision. In the first human muscle sample we found that we could easily tease 
out muscle strips that ran the whole length of the sample and these strips appeared to be continuous intact fibers. When the muscle strips were incubated in Krebs-Henseleit medium, they contracted to a much shortened length and thus we thought that it would be necessary to mount them at resting length during incubation. To do this we constructed the two sets of clamps described in Methods and the muscle was incubated with a clamp on each end of the muscle fiber strip. Besides maintaining the muscle strip at in vivo length, this procedure has the added presumed advantage of sealing the cut ends of the fibers so that intracellular contents do not leak out or extracellular material diffuse into the open ends of the fibers.

One of our initial objectives was to show that the human fiber strip preparations were metabolically viable. We felt that the size of the muscle fiber strip was probably a critical parameter in maintaining a viable preparation so ATP concentrations of muscle fiber strips of different sizes were determined after incubation. The optimal weight of the muscle strips appeared to be between 50 and $100 \mathrm{mg}$. Larger strips probably have impaired oxygen and/or nutrient diffusion while smaller strips are not as viable because the number of damaged fibers on the surface of the preparation becomes a larger proportion of the total.

Although it was important to show that our muscle fiber strip preparation was metabolically viable and structurally intact, the most important requirement of the system for the studies that we planned was responsiveness to insulin. To establish that insulin does stimulate glucose transport in this preparation we measured 3-O-methylglucose and 2-deoxyglucose uptake under basal and insulin-stimulated conditions. The results shown for normal weight subjects clearly demonstrates the suitability of this preparation for these studies since glucose transport was accelerated by insulin in eight of the nine nonobese subjects. Although we cannot rule out insulin acting through IGF-I receptors at maximal insulin concentrations, the stimulation of glucose transport at normal physiological insulin concentrations suggest that the response is mediated through the insulin receptor.

The rates of 3-O-methylglucose transport in human muscle $(8.1 \pm 0.6$ and $19.6 \pm 1.8 \mathrm{nmol} / \mathrm{min} \cdot \mathrm{g}$ for basal and insulinstimulated, respectively) are considerably lower than we observed in rat soleus muscle $(24 \pm 7$ and $100 \pm 7 \mathrm{nmol} / \mathrm{min} \cdot \mathrm{g}$ for basal and insulin-stimulated, respectively) but the extent of insulin stimulation is comparable in rat and human muscle. The rate of transport that we measure in our in vitro muscle fiber strips may well be within the normal range of in vivo transport of glucose since Yki-Jarvinen et al. (15) measured glucose disposal in muscle of the forearm to be in the range of $5-250 \mathrm{nmol} / \mathrm{min} \cdot \mathrm{g}$ muscle (see Fig. 5 of reference 15) and the rate of glucose disposal is likely limited by the rate of glucose transport.

The major purpose in developing this in vitro human muscle fiber strip preparation was to provide a system to investigate the mechanisms responsible for insulin resistance in muscle. The results obtained on muscle from obese and diabetic subjects demonstrate the importance of the preparation. Tissue from morbidly obese subjects with or without NIDDM were not responsive to insulin. In addition, maximally insulin stimulated 3-O-methylglucose transport was significantly lower in normal-obese and diabetic-obese muscle samples compared to those from nonobese subjects, but there was no difference in transport rates between the two obese groups.
These results suggest that morbid obesity causes a severe insulin resistance in muscle tissue but the defect in insulin action is the same in subjects with or without NIDDM.

The finding that basal glucose transport does not change in an insulin-resistant state seems in agreement with the in vivo data of Baron et al. (16). They found that non-insulin-mediated glucose uptake was elevated in type II diabetic subjects but this was a result of the hyperglycemia and when the plasma glucose concentration was matched in control subjects the basal rate of glucose utilization was the same in control and diabetic subjects.

Sinha et al. $(17,18)$ measured glucose transport into adipocytes and Caro et al. (19) measured amino acid transport in hepatocytes isolated from the same groups of subjects as those in the present study. In contrast to the results in muscle, insulin responsiveness was depressed somewhat in the nondiabetic-obese group but glucose transport rate and insulin responsiveness were depressed even further in the morbidly obese patients with NIDDM. These results from muscle, adipose tissue, and liver from the same groups of subjects demonstrate that not all tissues are altered to the same extent in these insulin-resistant states and it is not possible to investigate one tissue or cell type and extrapolate to the response of other tissues. Likewise a given tissue may respond differently to each specific insulin action. For example, it is well accepted that adipose tissue in NIDDM is resistant to insulin with respect to glucose transport but inhibition of lipolysis is normal (20). Also, in a lesser degree of obesity, insulin sensitivity was decreased but responsiveness was normal with regards to glycogen synthase activation in skeletal muscle (21).

We have been especially interested in the molecular mechanisms that cause insulin resistance in skeletal muscle from these patients (22). Insulin binding by solubilized insulin receptors was equally decreased in skeletal muscle from obese patients with or without NIDDM. Likewise, insulin receptor kinase activity was decreased in obesity without any appreciable additional defect when obesity was associated with NIDDM. Thus, in skeletal muscle from individuals with severe obesity, a defect in insulin-stimulated glucose transport and insulin receptor kinase activity appears to be present. A mechanistic relationship between these two processes is only speculative at this time. Alternatively, a decrease in the number of intracellular glucose transporters would also explain the insulin resistance in our patients as has been observed in adipocytes from animal models of insulin resistance (23-26).

In summary, we have developed an in vitro incubated human muscle fiber strip preparation that is structurally intact, metabolically viable, and responsive to insulin. With this preparation we have shown that maximal glucose transport into muscle of morbidly obese individuals is depressed and insulin responsiveness is decreased. We believe this in vitro muscle preparation will prove to be invaluable in clinical investigations of metabolic disturbances such as obesity and NIDDM.

\section{Acknowledgments}

The expert technical assistance of J. A. Wells is gratefully acknowledged.

This work was supported by grants from the American Diabetes Association and the National Institutes of Health (1 PO1 DK3629601A1). 


\section{References}

1. Olefsky, J. M., T. P. Ciaraldi, and O. G. Kolterman. 1985. Mechanisms of insulin resistance in non-insulin-dependent (type II) diabetes. Am. J. Med. 79(Suppl. 3B):12-22.

2. DeFronzo, R. A., R. Gunnarsson, O. Bjorkman, M. Olsson, and J. Wahren. 1985. Effects of insulin on peripheral and splanchnic glucose metabolism in noninsulin-dependent (Type II) diabetes mellitus. J. Clin. Invest. 76:149-155.

3. Reaven, G. M., Y. I. Chen, A. M. Coulston, M. S. Greenfield, C. Hollenbeck, C. Lardinois, G. Liu, and H. Schwartz. 1983. Insulin secretion and action in non-insulin-dependent diabetes mellitus. Am. J. Med. 75:85-93.

4. Rizza, R. W., L. J. Mandarino, and J. E. Gerich. 1981. Mechanism and significance of insulin resistance in non-insulin-dependent diabetes mellitus. Diabetes. 30:990-995.

5. Brown, E. K., E. A. Settle, and A. M. van Rij. 1982. Food intake patterns of gastric bypass patients. J. Am. Diet. Assoc. 80:439-443.

6. National Diabetes Data Group. 1979. Classification and progress of diabetes mellitus and other categories of glucose intolerance. Diabetes. 23:1039-1056.

7. Crettaz, M., M. Prentki, D. Zoninetti, and B. Jeanrenaud. 1980. Insulin resistance in soleus muscle from obese Zucker rats: involvement of several defective sites. Biochem. J. 186:525-534.

8. Williamson, J. R. and B. E. Corkey. 1969. Assays of intermediates of the citric acid cycle and related compounds by fluorometric enzyme methods. Methods Enzymol. 13:434-513.

9. Wallberg-Henriksson, H., and J. O. Holloszy. 1985. Activation of glucose transport in diabetic muscle: responses to contraction and insulin. Am. J. Physiol. 249:C233-C237.

10. Lowenstein, J. M. 1972. Ammonia production in muscle and other tissues: the purine nucleotide cycle. Physiol. Rev. 52:382-414.

11. Kolterman, O. G., J. Insel, M. Saekaw, and J. M. Olefsky. 1980. Mechanism of insulin resistance in human obesity. Evidence for receptor and post-receptor defects. J. Clin. Invest. 65:1272-1284.

12. Zuniga-Guajardo, S., J. Jimenez, A. Angel, and B. Zinman. 1986. Effects of massive obesity on insulin sensitivity and insulin clearance and the metabolic response to insulin as assessed by the euglycemic clamp technique. Metab. Clin. Exp. 35:278-282.

13. Rabinowitz, D., and K. L. Zierler. 1962. Forearm metabolism in obesity and its response to intra-arterial insulin: characterization of insulin resistance and evidence for adaptive hyperinsulinism. J. Clin. Invest. 41:2173-2181.

14. Ciaraldi, F. P., O. G. Kolterman, and J. M. Olefsky. 1981. Mechanism of post-receptor defect in insulin action in human obesity: decrease in glucose transport system activity. J. Clin. Invest. 68:875880.

15. Yki-Jarvinen, H., A. A. Young, C. Lamkin, and J. E. Foley. 1987. Kinetics of glucose disposal in whole body and across the forearm in man. J. Clin. Invest. 79:1713-1719.

16. Baron, A. D., O. G. Kolterman, J. B. Lawrence, J. Mandarino, and J. M. Olefsky. 1985. Rates of non-insulin-mediated glucose up- take are elevated in type-II diabetic subjects. J. Clin. Invest. 76:17821788.

17. Sinha, M. K., L. G. Taylor, W. J. Pories, E. G. Flickinger, D. Meelheim, S. Atkinson, N. S. Sehgal, and J. F. Caro. 1987. Long-term effect of insulin on glucose transport and insulin binding in cultured adipocytes from normal and obese humans with and without non-insulin dependent diabetes. J. Clin. Invest. 80:1073-1081.

18. Sinha, M. K., W. J. Pories, E. G. Flickinger, D. Meelheim, and J. F. Caro. 1987. Insulin-receptor kinase activity of adipose tissue from morbidly obese humans with and without NIDDM. Diabetes. 36:620-625.

19. Caro, J. F., O. Ittoop, W. J. Pories, D. Meelheim, E. G. Flickinger, F. Thomas, M. Jenquin, J. F. Silverman, P. G. Khazanie, and M. K. Sinha. 1986. Studies on the mechanism of insulin resistance in the liver from humans with non-insulin-dependent diabetes: insulin action and binding in isolated hepatocytes, insulin receptor structure, and kinase activity. J. Clin. Invest. 78:249-258.

20. Yki-Jarvinen, H., K. Kubo, J. Zawadzki, S. Lillioja, A. Young, W. Abbott, and J. E. Foley. 1987. Dissociation of in vitro sensitivities of glucose transport and antilipolysis to insulin in NIDDM. Am. J. Physiol. 253:E300-E304.

21. Evans, D. J., R. Murray, and A. H. Kissebah. 1984. Relationship between skeletal muscle insulin resistance, insulin-mediated glucose disposal, and insulin binding. Effects of obesity and body fat topography. J. Clin. Invest. 74:1515-1525.

22. Caro, J. F., M. S. Sinha, S. M. Raju, O. Ittoop, W. J. Pories, E. G. Flickinger, D. Meelheim, and G. L. Dohm. 1987. Insulin receptor kinase in human skeletal muscle from obese subjects with and without noninsulin dependent diabetes. J. Clin. Invest. 79:1330-1337.

23. Karnieli, E., P. J. Hissin, I. A. Simpson, L. Salans, and S. W. Cushman. 1981. A possible mechanism of insulin resistance in the rat adipose cell in streptozotocin-induced diabetes mellitus: depletion of intracellular glucose transport systems. J. Clin. Invest. 68:811-814.

24. Hissin, P. J., J. E. Foley, L. J. Wardzala, E. Karnieli, I. A. Simpson, L. B. Salans, and S. W. Cushman. 1982. Mechanism of insulin-resistant glucose transport activity in the enlarged adipose cell of the aged, obese rat: relative depletion of intracellular glucose transport systems. J. Clin. Invest. 70:780-790.

25. Salans, L. B., J. E. Foley, L. J. Wardzala, and S. W. Cushman. 1981. Effects of dietary composition on glucose metabolism in rat adipose cells. Am. J. Physiol. 240:E175-183.

26. Hissin, P. J., E. Karnieli, I. A. Simpson, L. B. Salans, and S. W. Cushman. 1982. A possible mechanism of insulin resistance in the rat adipose cell with high-fat/low-carbohydrate feeding: depletion of intracellular glucose transport systems. Diabetes. 31:589-592.

27. Lowry, O. H., N. J. Rosebrough, A. L. Farr, and R. J. Randall. 1951. Protein measurement with the Folin phenol reagent. J. Biol. Chem. 193:265-275.

28. Dryer, R. L. 1970. The lipids. In Fundamentals of Clinical Chemistry. N. W. Tietz, editor. W. B. Saunders Co., Philadelphia. 302-361. 